\title{
In vitro and in vivo effects of the probiotic Escherichia coli strain M-17: immunomodulation and attenuation of murine colitis
}

\author{
Leo R. Fitzpatrick ${ }^{1}$, Jeffrey Small ${ }^{1}$, Robert A. Hoerr ${ }^{2}$, Eileen F. Bostwick ${ }^{2}$, Lynn Maines ${ }^{3}$ \\ and Walter A. Koltun ${ }^{4}$ \\ ${ }^{1}$ Department of Pharmacology, Penn State College of Medicine, 1214 Research Boulevard, Hummelstown, PA 17036, USA \\ ${ }^{2}$ The BioBalance Corporation, New York, NY, USA \\ ${ }^{3}$ Apogee Biotechnology Corporation, Hershey, PA, USA \\ ${ }^{4}$ Department of Surgery, Penn State College of Medicine, Hershey, PA, USA
}

(Received 4 June 2007 - Revised 28 September 2007 - Accepted 28 November 2007 - First published online 18 February 2008)

We examined the in vitro and in vivo effects of a probiotic, Escherichia coli strain M-17 (EC-M17), on NF- $\kappa \mathrm{B}$ signalling, cytokine secretion and efficacy in dextran sulfate sodium (DSS)-induced murine colitis. NF- $\kappa B$ signalling was assessed using an NF- $\mathrm{B}$ luciferase reporter cell line that was stimulated with TNF- $\alpha(100 \mathrm{ng} / \mathrm{ml})$. p65 Nuclear binding and cytokine secretion (TNF- $\alpha$, IL-1 $\beta$ and IL-6) were evaluated using a RAW 264.7 macrophage cell line that was exposed to lipopolysaccharide (LPS; $5 \mu \mathrm{g} / \mathrm{ml}$ ). Mice were administered vehicle, EC-M17, metronidazole, or EC-M17 plus metronidazole for $13 \mathrm{~d}$. During the final $6 \mathrm{~d}$, mice also received $2 \%$ DSS. Parameters evaluated included disease activity index

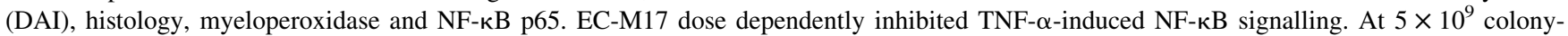
forming units/ml, EC-M17 inhibited NF-kB by $>95 \%$. LPS-induced nuclear p65 binding was significantly inhibited $(78 \% ; P<0.05)$ in RAW 264.7 macrophages at $1 \times 10^{8}$ colony-forming units/ml. EC-M17 also inhibited (by $>90 \%$ ) the LPS-induced secretion of TNF- $\alpha$, IL-1 $\beta$ and IL-6. In mice with DSS-induced colitis, EC-M17, metronidazole, and EC-M17 plus metronidazole significantly reduced DAI and colonic histology scores. Both EC-M17 and metronidazole reduced colonic IL-12, IL-6, IL-1 $\beta$ and interferon- $\gamma$. The combination of EC-M17 plus metronidazole resulted in more substantial cytokine reductions than were found with either treatment alone, and combination therapy significantly $(P<0.05$ in both cases) reduced IL-1 $\beta$ compared with EC-M17 and colonic histology scores compared with metronidazole. Alone, and in combination with metronidazole, EC-M17 improved murine colitis, probably due to an inhibitory effect on NF- $\mathrm{KB}$ signalling.

Probiotics: Escherichia coli strain M-17: Cytokines: Nuclear factor-кB: p65

The pathogenesis of inflammatory bowel disease (IBD) is clearly associated with microflora-host interactions that produce inflammatory mediators ${ }^{(1,2)}$. It has been demonstrated that some non-invasive organisms are capable of inducing epithelial cells to produce chemotactic cytokines (for example, IL-8) with resultant neutrophil migration ${ }^{(3)}$. Further, experimental evidence suggests that the presence of human commensal bacteria in genetically susceptible individuals is essential in the pathogenesis of $\mathrm{IBD}^{(1)}$. Not surprisingly, therefore, therapies have been sought to modify the intestinal flora; one of these is the administration of probiotics.

Probiotics are live micro-organisms which, when ingested, can confer health benefits ${ }^{(4)}$. Various probiotics are now moving into the mainstream of medical therapy for pouchitis ${ }^{(1,2)}$. Moreover, some evidence of probiotic efficacy has been reported in the treatment of $\mathrm{IBD}^{(1,2)}$. Typically, probiotics are various strains of Lactobacillus or Bifidobacteria species. They exist as either single entities or as combination products $^{(1,2)}$.
Immunomodulatory actions, such as the reduction of pro-inflammatory cytokines (for example, TNF- $\alpha$, interferon (IFN)- $\gamma$ ), and the increased secretion of regulatory cytokines (for example, IL-10), have been suggested as one of the mechanisms of action for probiotics ${ }^{(1)}$. The transcription factor NF-кB, once separated from its inhibitory protein (ІкB), translocates into the nucleus where it activates genes encoding immunologically relevant proteins (for example, TNF- $\alpha$, IL- $1 \beta$ and IL-6) ${ }^{(5-7)}$. NF- $\mathrm{KB}$ is thought to play a key role in the pathogenesis of intestinal inflammation. Evidence supporting the pro-inflammatory role of NF- $\mathrm{NB}$ comes from both animal models of enteric inflammation and from patients with IBD. It is not surprising, therefore, that the inhibition of NF- $\mathrm{KB}$ has been proposed as an important therapeutic target for IBD ${ }^{(8-11)}$. Recently, it was reported that probiotics could inhibit the NF- $\mathrm{B}$ signal transduction system ${ }^{(4,12)}$.

Several different probiotic agents have demonstrated evidence of efficacy in the dextran sulfate sodium (DSS)-induced colitis model ${ }^{(13,14)}$. The pathogenesis of DSS-induced colitis

Abbreviations: cfu, colony-forming unit; DAI, disease activity index; DSS, dextran sulfate sodium; EC-M17, Escherichia coli strain M-17; IBD, inflammatory bowel disease; IFN, interferon; LPS, lipopolysaccharide; MPO, myeloperoxidase.

* Corresponding author: Associate Professor Leo R. Fitzpatrick, fax +1 717531 5013, email lfitzpatrick@psu.edu 
involves a defect in epithelial barrier function, as related to the direct cytotoxic effect of $\operatorname{DSS}^{(15,16)}$. Changes in epithelial barrier function, as measured by the permeability to Evan's blue dye, can be found early during the time course of DSS-induced colitis ${ }^{(17)}$. This alteration in the colonic mucosal barrier subsequently leads to the influx of various inflammatory cells, macrophage activation and pro-inflammatory cytokine production $^{(15,16)}$. Additionally, the nuclear expression of the p65 subunit of NF- $\kappa \mathrm{B}$ has previously been shown to be upregulated during DSS-induced colitis and is thought to play a critical role in promoting intestinal inflammation ${ }^{(18,19)}$.

Escherichia coli strain M-17 (EC-M17) is a novel probiotic agent with beneficial effects on the gastrointestinal tract ${ }^{(20)}$. EC-M17 is believed to be a direct descendant of the M17 strain first identified by the Russian bacteriologist L. G. Peretz in 1933. The original strain was maintained by the Tarasevich Institute of the Russian Ministry of Health and has been used extensively in humans as a therapy for gastrointestinal diseases and infections. The Russian literature documents the use of EC-M17 in thousands of individuals, mostly for the treatment of dysentery ${ }^{(21,22)}$.

The first goal of the present study was to examine the in vitro effects of EC-M17 on the NF- $\mathrm{BB}$ signalling system and on the secretion of pro-inflammatory cytokines (IL-1 $\beta$, IL-6, TNF- $\alpha$ ). A second goal of the present study was to evaluate the effects of EC-M17 on relevant clinical, histological and biochemical parameters in the murine DSS colitis model. In conjunction with the DSS colitis model, the effects of EC-M17 on nuclear p65 expression and relevant proinflammatory cytokines were also evaluated in vivo. A third goal was to compare the effects of EC-M17 with those produced by a known therapy for intestinal inflammation (i.e. pouchitis, IBD), metronidazole. Finally, a fourth goal of the present study was to evaluate the effects of EC-M17 plus metronidazole in DSS-induced colitis.

\section{Experimental methods}

\section{Escherichia coli strain M-17 information}

EC-M17 is a non-pathogenic bacterium of the family Enterobacteriaciae. It is a non-spore-forming gram-negative rod of the serotype $\mathrm{O} 2$ with flagellar antigen $\mathrm{H}$ type 41 . EC-M17 is a facultative anaerobic bacillus that converts nitrates to nitrites, and is oxidase-negative and catalase-positive. Except for the presence of type 1 fimbriae, samples of EC-M17 are negative for all other virulence factors. American Type Culture Collection (ATCC) 202226 is the designation given to the parental seed stock of EC-M17 that was deposited with the American Type Culture Collection. EC-M17 is produced for research use, using a standard microbiological fermentation process.

Whole genome shotgun sequencing of a naturally occurring naladixic acid-resistant substrain of the parental EC-M17 strain has been successfully completed by the Pathogenomics Sequence Analysis Facility of the University of Minnesota to approximately an 8-fold coverage of the genome (V Kapur, unpublished results). To date, no direct comparison has been done to compare the sequence of EC-M17 with that of E. coli Nissle 1917. However, according to a published report, the Nissle strain differs from M17 in both serotype (O6 v. O2 for M17) and flagellar $\mathrm{H}$ antigen $(\mathrm{H} 1 v . \mathrm{H} 41)^{(23)}$.

\section{Reagents}

DSS of molecular weight 36000 to $50000 \mathrm{Da}$ was obtained from MP Biomedicals (Aurora, OH, USA). Key reagents for the myeloperoxidase (MPO) assay, which include $3,3^{\prime}, 5,5^{\prime}$ tetramethylbenzidine, $N, N$ dimethylformamide, $\mathrm{H}_{2} \mathrm{O}_{2}$ and hexadecyl-trimethyl-ammonium bromide, were obtained from Sigma Chemical Company (Saint Louis, MO, USA). Metronidazole was also obtained from Sigma. An NF-кB p65 antibody (sc-109) was obtained from Santa Cruz Biotechnology Inc. (Santa Cruz, CA, USA). Mouse cytokine ELISA kits (IL-1 $\beta$, IL-6, IL-10, IL-4) were obtained via Pierce Endogen Inc. (Rockford, IL, USA). The IL-12 mouse ELISA kit was purchased from Biosource International (Camarillo, CA, USA). The TransAM ${ }^{\mathrm{TM}}$ NF-кB p65 assay kit was obtained from Active Motif (Carlsbad, CA, USA). The BioBalance Corporation (New York, NY, USA) provided the EC-M17 as a $5 \times 10^{11}$ colony-forming units $(\mathrm{cfu}) / \mathrm{ml}$ stock suspension in $0.6 \%$ saline.

\section{Effects of Escherichia coli strain $M-17$ in an nuclear factor- $\kappa B$ reporter gene cell line}

A NF-кB reporter stable cell line, derived from human 293T embryonic kidney cells, was obtained from Panomics (Redwood City, CA, USA). Integrated into the cell line is a luciferase reporter construct that is regulated by six copies of the $\mathrm{NF}-\kappa \mathrm{B}$ response element. For these studies, the cells were plated into twenty-four-well culture plates and grown to confluence. The medium was then removed and replaced with serum-free medium for $16 \mathrm{~h}$. Cells were treated with vehicle $(0.6 \%$ saline $)$ or EC-M17 $\left(1 \times 10^{8} \mathrm{cfu} / \mathrm{ml}\right)$, immediately before activating the NF- $\mathrm{BB}$ signalling pathway with the addition of TNF- $\alpha(100 \mathrm{ng} / \mathrm{ml})$. All treatments were performed in triplicate. After $6 \mathrm{~h}$, the cells were washed and lysed before the luciferase activity was quantified as relative light intensity. Light intensity was measured using an assay kit from Promega Corporation (Madison, WI, USA) and a Perkin Elmer HTS $7000+$ Bioassay plate reader in the luminescence mode.

\section{Effects of Escherichia coli strain M-17 in a RAW 264.7 macrophage cell line}

The RAW 264.7 mouse macrophage cell line was obtained from the American Type Culture Collection (ATCC, Rockville, MD, USA). RAW 264.7 cells were grown in Dulbecco's modified Eagle's medium containing $10 \%$ fetal bovine serum. The lipopolysaccharide (LPS) stimulation studies were conducted at a cell density of $2 \times 10^{6} / \mathrm{ml}$. EC-M17 was added to the macrophage cell culture system, at a concentration of $1 \times 10^{8} \mathrm{cfu} / \mathrm{ml}$, just before LPS $(5 \mu \mathrm{g} / \mathrm{ml})$. For the NF- $\mathrm{B}$ p65 measurement, nuclear extracts were obtained from cells either immediately $(0 \mathrm{~h})$ or $3 \mathrm{~h}$ after LPS-stimulation. A protein determination of the nuclear extracts was done with the Bio-Rad protein assay (Bio-Rad Laboratories, Hercules, CA, USA). For the p65 analysis, $10 \mu \mathrm{g}$ protein was utilised per sample. The nuclear binding of p65 was measured with the 
TransAM ${ }^{\mathrm{TM}}$ NF- $\mathrm{kB}$ p65 assay kit, according to the manufacturer's instructions.

For the cytokine secretion experiments, after 0 or $4 \mathrm{~h}$ of LPS exposure, the culture medium was collected for the measurement of cytokines (TNF- $\alpha$, IL-1 $\beta$ and IL-6) by ELISA (Pierce-Endogen), according to the manufacturer's directions. Probiotic-conditioned culture media $(\mathrm{CM})$ was prepared by adding EC-M17 to the macrophage culture media for $5 \mathrm{~min}$ or $2 \mathrm{~h}$. The media was then collected and centrifuged at $10000 \mathrm{rpm}$ for $10 \mathrm{~min}$. Next, the CM was passed through a $0.22 \mu \mathrm{m}$ filter before use in cytokine secretion experiments. In order to heat kill EC-M17 (HK), the probiotic was boiled at $100^{\circ} \mathrm{C}$ for $20 \mathrm{~min}$. Then, the heat-killed EC-M17 was centrifuged at $10000 \mathrm{rpm}$. The cellular pellet was washed in PBS and re-centrifuged. The pellet was then re-suspended in a sufficient quantity of saline to achieve a final concentration of $1 \times 10^{8} \mathrm{cfu} / \mathrm{ml}$. HK and CM were used in cytokine secretion studies with the RAW 264.7 cell line, as described above. $\mathrm{CM}$ was used at a final concentration of $10 \%(\mathrm{v} / \mathrm{v})$. In some experiments, we also evaluated whether metronidazole $(50 \mu \mathrm{g} / \mathrm{ml})$ could inhibit cytokine secretion.

\section{Mice}

Male C57 BL/6 mice were obtained from The Jackson Laboratory (Bar Harbor, ME, USA). Three separate DSS-induced colitis studies were conducted, all using 9-11-week-old mice. The initial study compared the effects of three different dosages of EC-M17. The subsequent study compared the effects of EC-M17 alone, metronidazole alone, and the combination of EC-M17 and metronidazole. An additional study was conducted to analyse the NF-кB p65 subunit in murine colonic samples.

\section{Preparation of Escherichia coli strain $M-17$} and metronidazole

A $0.6 \%$ saline solution (vehicle) was prepared by diluting sterile $0.9 \%$ saline (Hospira Inc., Lake Forest, IL, USA) with sterile water (Abbot Laboratories, North Chicago, IL, USA). Subsequently, the $1 \times 10^{11} \mathrm{cfu} / \mathrm{ml}$ stock suspension of EC-M17 was diluted with $0.6 \%$ saline so as to yield the final EC-M17 concentrations used $\left(5 \times 10^{7} \mathrm{cfu} / \mathrm{ml}, 1 \times 10^{8} \mathrm{cfu} / \mathrm{ml}\right.$, $5 \times 10^{8} \mathrm{cfu} / \mathrm{ml}$, and $\left.5 \times 10^{9} \mathrm{cfu} / \mathrm{ml}\right)$. The $0.6 \%$ saline solution was used as the vehicle treatment solution in the colitis studies. Metronidazole was suspended in $0.6 \%$ saline and then heated with hot water for approximately $2 \mathrm{~min}$. Using this method, metronidazole became completely soluble in the vehicle. Based on the relevant literature, a $40 \mathrm{mg} / \mathrm{kg}$ dose of metronidazole was used ${ }^{(24)}$.

\section{Escherichia coli strain M-17 dosage assessment in dextran} sulfate sodium-induced colitis in mice

During the first $7 \mathrm{~d}$ of the study, mice were given Milliporefiltered drinking water. Throughout this initial $7 \mathrm{~d}$ period, mice were dosed once daily with vehicle (at a dose volume of $5 \mathrm{ml} / \mathrm{kg} ; n 8)$, with EC-M17 $(5 \mathrm{ml} / \mathrm{kg})$ at a $5 \times 10^{7} \mathrm{cfu} / \mathrm{ml}$ concentration $(n 8)$, with EC-M17 $(5 \mathrm{ml} / \mathrm{kg})$ at a $5 \times 10^{8}$ $\mathrm{cfu} / \mathrm{ml}$ concentration $(n 8)$ or with EC-M17 $(5 \mathrm{ml} / \mathrm{kg})$ at a $5 \times 10^{9} \mathrm{cfu} / \mathrm{ml}$ concentration ( $n$ 8). The dosing was by orogastric administration. EC-M17 or vehicle dosing continued for the next $6 \mathrm{~d}$ while $2 \%$ DSS was administered in the drinking water. One group of animals received water without DSS. The severity of colitis was assessed by disease activity index (DAI) measurements during the $13 \mathrm{~d}$ study period.

\section{Disease activity index}

A DAI was determined with a 0 to 4 point severity scale, based on stool consistency and evidence of intestinal bleeding. The method used (Table 1) was that of Murthy et al. ${ }^{(25)}$ with slight modifications ${ }^{(26)}$. DAI were determined on days $0,2,4$, $6,8,10,12$ and 13. The DAI was calculated as the sum of the scores for stool consistency and evidence of gastrointestinal bleeding divided by $2^{(25)}$. The presence of occult blood was determined on faecal smears by a hemoccult fecal occult blood kit (Beckman-Coulter Inc., Brea, CA, USA).

The comparative effects of Escherichia coli strain $M-17$, metronidazole, and Escherichia coli strain M-17 plus metronidazole in dextran sulfate sodium-induced colitis in mice

During the first $7 \mathrm{~d}$ of the study, mice were given Milliporefiltered drinking water. The water consumption by mice was determined during this period. During this initial $7 \mathrm{~d}$ period, mice were dosed once daily with vehicle (two groups $n 6$ and $n 9$; at a dose volume of $5 \mathrm{ml} / \mathrm{kg}$ ), with EC-M17 $(5 \mathrm{ml} / \mathrm{kg})$ at a $5 \times 10^{9} \mathrm{cfu} / \mathrm{ml}$ concentration $(n 10)$, with metronidazole $(40 \mathrm{mg} / \mathrm{kg} ; n$ 10) or with both EC-M17 $(5 \mathrm{ml} / \mathrm{kg})$ at a $5 \times 10^{9} \mathrm{cfu} / \mathrm{ml}$ concentration and metronidazole $(40 \mathrm{mg} / \mathrm{kg} ; n \mathrm{10})$. The dosing was by orogastric administration. EC-M17, metronidazole, EC-M17 plus metronidazole, or vehicle dosing continued for the next $6 \mathrm{~d}$, while $2 \%$ DSS was administered in drinking water. One group of animals received water without DSS. Water consumption data were also collected during this phase of the study. DAI were determined on days $0,2,4,6,8,10,12$ and 13 .

\section{Colonic histological evaluation}

On day 13, these mice were euthanised with carbon dioxide. The colon was rapidly excised, and the colon length was measured. Subsequently, the colon was opened and faecal material removed by thorough rinsing in $0.9 \%$ saline. A $2.5 \mathrm{~cm}$ segment of distal colon was immediately fixed in $10 \%$ buffered formalin, and the tissue was processed for a histological evaluation.

Histological damage was determined on a forty-point severity scale (Table 2). The percentage area of involvement was

Table 1. Disease activity index scoring system

\begin{tabular}{lll}
\hline Score & Stool consistency & $\begin{array}{l}\text { Occult blood (negative or } \\
\text { positive) or gross bleeding }\end{array}$ \\
\hline 0 & Normal & Negative \\
1 & Loose stool & Negative \\
2 & Loose stool & Positive \\
3 & Diarrhoea & Positive \\
4 & Diarrhoea & Gross bleeding \\
\hline
\end{tabular}

\footnotetext{
$5 \times 10 \mathrm{cfu} / \mathrm{ml}$ concentration ( $n$ 8). The dosing was by
} 
Table 2. Histological scoring system

\begin{tabular}{lcl}
\hline Feature scored & Score & Description \\
\hline Inflammation severity & 0 & None \\
& 1 & Mild \\
& 2 & Moderate \\
Inflammation extent & 3 & Severe \\
& 0 & None \\
Crypt damage & 1 & Mucosa \\
& 2 & Mucosa and submucosa \\
& 3 & Transmural \\
Percentage involvement & 1 & $1 / 3$ of crypt damaged \\
& 2 & $2 / 3$ of crypt damaged \\
& 3 & Crypts lost, surface \\
& & epithelium present \\
& 4 & Crypts and surface \\
& 0 & epithelium lost \\
& 1 & $1-25$ \\
& 2 & $26-50$ \\
& 3 & $51-75$ \\
& 4 & $76-100$
\end{tabular}

determined with a $25 \mathrm{~mm}$ ocular grid that was attached to an Olympus CH light microscope (Olympus, Center Valley, PA, USA). All histological evaluations were done at $400 \times$ magnification and the calculation of histology scores involved the extent of inflammation, infiltration and crypt damage. For example, if there was a dense infiltrate of inflammatory cells that covered $90 \%$ of the grid area, the inflammation severity score would be 12 . This reflects the product of the severity of inflammation (sub-score $=3$ ) and the percentage involvement (sub-score $=4$ ). If the inflammation extended into the submucosa and was found in $80 \%$ of the grid area, the inflammation extent score would be 8 . This reflects the product of the inflammation extent (sub-score $=2$ ) and the percentage involvement (sub-score $=4$ ). If the crypts were entirely lost in $100 \%$ of the area being evaluated, the crypt damage score would be 16 . This reflects the product of the crypt damage (sub-score $=4$ ) and the percentage involvement (sub-score $=4$ ). Therefore, the total histology score for this area of the slide would be 36; 12 (inflammation severity) +8 (inflammation extent) +16 (crypt damage). Six areas on each histology slide were evaluated and a mean histology score was determined for each slide. The evaluation was done on coded slides so that the investigator (L. R. F.) was unaware of the treatment group. Other investigators have used this scoring system in conjunction with the DSS-induced colitis model ${ }^{(27,28)}$.

\section{Measurement of myeloperoxidase and cytokines}

A $2.5 \mathrm{~cm}$ segment of colon, adjacent to that obtained for histological evaluation, was used to measure MPO and various cytokines from colonic homogenates, as described previously by the principal investigator ${ }^{(26,29)}$. Briefly, the homogenates were centrifuged at $10000 \mathrm{rpm}$ for $15 \mathrm{~min}$. The pellet was retained for measurement of MPO by the $3,3^{\prime}, 5,5^{\prime}$ tetramethylbenzidine method. The supernatant fraction was sampled and frozen at $-70^{\circ} \mathrm{C}$ for the subsequent determination of colonic cytokine levels. The following cytokines were measured in these colonic samples: IL-12, IFN- $\gamma$, IL- $1 \beta$, IL-6, IL-10 and IL-4, using mouse cytokine ELISA kits.
Western blot analysis of the nuclear factor- $\kappa$ B p65 subunit in murine colonic samples

In a separate study, fourteen mice were treated, as described here: (1) vehicle for $13 \mathrm{~d}$ while given filtered drinking water for the entire time period ( $n$ 2), (2) EC-M17 $(5 \mathrm{ml} / \mathrm{kg}$ of a $5 \times 10^{9} \mathrm{cfu} / \mathrm{ml}$ concentration) for $13 \mathrm{~d}$ while maintained on filtered water for the entire time period $(n 3)$, (3) vehicle for $13 \mathrm{~d}$ while given $2 \%$ DSS in drinking water for the final $6 \mathrm{~d}$ $(n 5)$ or $(4)$ EC-M17 $\left(5 \mathrm{ml} / \mathrm{kg}\right.$ of a $5 \times 10^{9} \mathrm{cfu} / \mathrm{ml}$ concentration) for $13 \mathrm{~d}$, while maintained on $2 \%$ DSS for the final $6 \mathrm{~d}(n 4)$. Mice were euthanised on study day 13 and colon samples were snap-frozen in liquid $\mathrm{N}_{2}$ before the collection of nuclear extracts from colonic homogenates. Briefly, for the preparation of nuclear extracts, the colonic tissue samples were cut into tiny pieces and washed with $500 \mu \mathrm{l}$ cold PBS. The sample was centrifuged at $7000 \mathrm{rpm}$ (i.e. for $6 \mathrm{~min}$ at $4^{\circ} \mathrm{C}$ ). Then, lysis buffer (10 mM-HEPES, $10 \mathrm{~mm}-\mathrm{KCl}, 1 \mathrm{~mm}$-dithiothreitol, $0.1 \mathrm{~mm}-$ EDTA, $0.5 \mathrm{~mm}$-PMSF (phenylmethanesulfonyl fluoride), $1 \%$ IGEPAL ${ }^{\circledR}$ ((octylphenoxy)polyethoxyethanol, octylphenylpolyethylene glycol), 1X Complete ${ }^{\circledR}$ protease inhibitor tablets (Roche Diagnostics, Manheim, Germany), aprotinin $(2 \mu \mathrm{g} / \mathrm{ml})$, leupeptin $(2 \mu \mathrm{g} / \mathrm{ml})$ and benzamidine $(0.5 \mu \mathrm{g} / \mathrm{ml}))$ was added to the tissue pellets. The samples were then incubated on ice for $30 \mathrm{~min}$. The tissue pellets were then homogenised with a tissue miser (Thermo Fisher Scientific Inc., Waltham, MA, USA). These samples were further homogenised with a pestle tissue homogeniser (Thermo Fisher Scientific Inc.) and then centrifuged at $14000 \mathrm{rpm}$ (i.e. for $10 \mathrm{~min}$ at $4^{\circ} \mathrm{C}$ ). The pellets were gently washed with lysis buffer without $1 \%$ IGEPAL. The washes were discarded and the pellets re-suspended with nuclear lysis buffer (20 mM-HEPES, $0 \cdot 4 \mathrm{M}-\mathrm{NaCl}, 1.5 \mathrm{~mm}-\mathrm{MgCl}_{2}, 25 \%$ glycerol, $0.2 \mathrm{~mm}$-dithiothreitol, $0.2 \mathrm{~mm}$-EDTA, $0.5 \mathrm{~mm}$-PMSF, $1 \%$ IGEPAL, aprotinin $(2 \mu \mathrm{g} / \mathrm{ml})$, leupeptin $(2 \mu \mathrm{g} / \mathrm{ml})$ and benzamidine $(0.5 \mu \mathrm{g} / \mathrm{ml}))$. The samples were periodically vortexed throughout a $30 \mathrm{~min}$ period and then centrifuged at $14000 \mathrm{rpm}$ $\left(15 \mathrm{~min}\right.$ at $\left.4^{\circ} \mathrm{C}\right)$. These supernatant fractions, which are the nuclear extracts, were retained for use in Western blot studies. A protein determination of these colonic extracts was done with the Bio-Rad protein assay (Bio-Rad Laboratories).

Western blots were performed using a standard technique that utilised $30 \mu \mathrm{g}$ protein per colonic sample. Briefly, 4-15\% 2-amino-2-(hydroxymethyl)propane-1,3-diol-HCl ready gels (Bio-Rad Laboratories) were run at $100 \mathrm{~V}$ for about $1 \mathrm{~h}$. Gels were then transferred onto PROTRAN ${ }^{\circledR}$ nitrocellulose membranes (Schleicher \& Schuell Bioscience Inc., Keene, NH, USA) and the blots were blocked with PBS-Tween containing $5 \%$ blotto (non-fat dried milk). Next, the blots were incubated in primary antibody (rabbit polyclonal antibody to p65), washed in PBS-Tween, and then exposed to an appropriate secondary antibody (goat-anti-rabbit). After another series of washes, equal amounts of an oxidising agent and a luminol reagent (Western Lightning; Perkin-Elmer Life Sciences Inc., Waltham, MA, USA) was applied for $1 \mathrm{~min}$. Subsequently, the blots were dried and exposed to Kodak Scientific Imaging XB-1 film. $\mathrm{NF}-\kappa \mathrm{B}$ p65 was expressed as a $65 \mathrm{kDa}$ protein as determined by internal molecular-weight standards (Bio-Rad Laboratories). For evaluating the levels of colonic p65 expression, a densitometry analysis was performed with a QuantiScan software program (Biosoft, Great Shelford, Cambs, UK). The p65 data were standardised to the actin levels in the nuclear samples, 
in order to account for any possible differences in the overall protein levels of the samples. The nuclear p65 expression data were normalised to the mean level found in vehicle- and water-treated mice, and it is reported as the fold increase compared with these data.

\section{Statistical analyses}

Statistical analyses were performed with GraphPad Prism computer software (GraphPad Software Inc., San Diego, CA, USA). Data are presented as means with their standard errors. Multiple treatment groups were analysed by one-way ANOVA, and then individual group comparisons were made by the NewmanKeuls multiple comparison test. To determine differences between two treatment groups, the Student's $t$ test was utilised. For DAI, data were compared using the Mann-Whitney test. A $P$ value $<0.05$ was considered statistically significant.

\section{Ethical considerations}

The relevant mouse colitis studies were approved by the Institutional Animal Care and Use Committee at the Penn State College of Medicine.

\section{Results}

Effects of Escherichia coli strain M-17 on the nuclear factor- $\kappa B$ reporter gene cell line

An initial in vitro dose-response study demonstrated that the EC-M17 probiotic could dose dependently attenuate TNF- $\alpha$ induced activation of a NF- $\kappa \mathrm{B}$-driven luciferase reporter gene system (Fig. 1 (a)). At $5 \times 10^{7} \mathrm{cfu} / \mathrm{ml}$, some inhibition $(29 \%$; $P<0.05)$ of NF-кB signalling was evident in human 293T embryonic kidney cells. However, more profound inhibition was seen in cells exposed to the $5 \times 10^{8} \mathrm{cfu} / \mathrm{ml}$ and $5 \times 10^{9} \mathrm{cfu} / \mathrm{ml}$ concentrations of EC-M17 (89 and $96 \%$ inhibition, respectively; $P<0.001$ in both cases). A $1 \times 10^{8} \mathrm{cfu} / \mathrm{ml}$ concentration of EC-M17 was selected for use in a follow-up

(a)
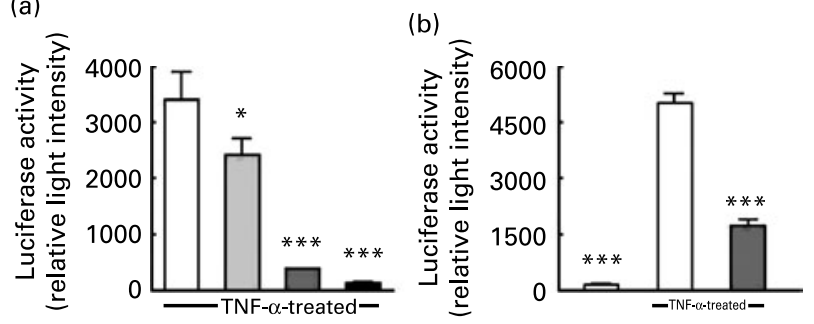

Fig. 1. The effects of Escherichia coli strain M-17 (EC-M17) on a NF-кB reporter gene assay in human 293T embryonic kidney cells that were activated by the addition of TNF- $\alpha(100 \mathrm{ng} / \mathrm{ml})$. EC-M17 was added to the assay immediately before TNF- $\alpha$ treatment. After a $6 \mathrm{~h}$ incubation, the luciferase activity was measured as relative light intensity, using a plate reader in the luminescence mode. (a) Cells were treated with vehicle $(0.6 \%$ saline; $\square)$ or three different concentrations of EC-M17 $\left(5 \times 10^{7}\right.$ colony-forming units $\left.(\mathrm{cfu}) / \mathrm{ml}(\square), 5 \times 10^{8} \mathrm{cfu} / \mathrm{ml}(\square), 5 \times 10^{9} \mathrm{cfu} / \mathrm{ml}(\square)\right)$. Mean value was significantly different from that of the vehicle-treated control group: ${ }^{\star} P<0.05$, ${ }^{\star * *} P<0.001$. (b) EC-M17 was used at $1 \times 10^{8} \mathrm{cfu} / \mathrm{ml}(\square)$ and two vehicle controls $(\square)$, one of which was a non-TNF- $\alpha$ control, were also included. ${ }^{\star * \star}$ Mean value was significantly different from that of the vehicle-treated, TNF- $\alpha$-treated control group $(P<0.001)$. Values are means from three experiments with their standard errors represented by vertical bars. study that included an untreated control group (vehicle). Even at this concentration, which was 50-fold less than the concentration of the solution used in the in vivo metronidazole comparative study in DSS-induced colitis (see below), TNF- $\alpha$-induced activation of NF-кB was significantly reduced $(65 \%$; $P<0 \cdot 001$ ) by the probiotic (Fig. 1 (b)). This reduction in NF$\kappa \mathrm{B}$ activation occurred without affecting cell viability, as determined by an MTS mitochondrial metabolism assay (Promega).

\section{Effects of Escherichia coli strain M-17 on the RAW 264.7 cell line}

After $3 \mathrm{~h}$ of exposure, EC-M17 alone (without LPS) only mildly increased the nuclear binding of p65 compared with vehicle. However, the LPS-induced increase in p65 binding was significantly inhibited $(78 \% ; P<0.05)$ by EC-M17 at $1 \times 10^{8} \mathrm{cfu} / \mathrm{ml}$ (Fig. 2 (a)). A confirmation of assay specificity was demonstrated by complete inhibition of p65 binding by a wild-type oligonucleotide control.

Cytokine secretion in this macrophage cell line was essentially near zero at baseline. After 4 h, EC-M17 only mildly stimulated secretion (data not shown). By comparison, treatment with LPS resulted in substantial increases in the secretion of pro-inflammatory cytokines (Fig. 2 (b), (c) and (d)). Live EC-M17 significantly inhibited $(>90 \% ; P<0.05)$ the LPS-induced secretion of TNF- $\alpha$, IL- $1 \beta$ and IL- 6 , when compared with LPS-treated cells exposed only to vehicle. Metronidazole $(50 \mu \mathrm{g} / \mathrm{ml})$, however, when exposed to RAW 264.7 cell cultures, did not reduce LPS-stimulated cytokine secretion (data not shown). Neither heat-killed EC-M17, nor EC-M17 conditioned media, effectively reduced cytokine secretion in LPS-treated macrophages (Fig. 2 (b), (c) and (d)). In these studies (Fig. 2), at $1 \times 10^{8} \mathrm{cfu} / \mathrm{ml}$, EC-M17 did not affect macrophage viability as determined by the trypan blue exclusion method.

The effects of different doses of Escherichia coli strain M-17 in dextran sulfate sodium-induced colitis

The effects of three different dosages of EC-M17 on mean DAI scores were compared on the final day of the study (day 13). It was observed that $5 \mathrm{ml} / \mathrm{kg}$ of both $5 \times 10^{8} \mathrm{cfu} / \mathrm{ml}$ and $5 \times 10^{9} \mathrm{cfu} / \mathrm{ml}$ of EC-M17 significantly reduced mean DAI scores when compared with vehicle in DSS-treated mice $(34.8 \%(P<0.05)$ and $43.5 \%(P<0.05)$, respectively). The lowest concentration of EC-M17 $\left(5 \times 10^{7} \mathrm{cfu} / \mathrm{ml}\right)$ did not significantly reduce the mean DAI. Therefore, the $5 \times 10^{9} \mathrm{cfu} / \mathrm{ml}$ concentration of EC-M17 was selected for use in the comparative study with metronidazole.

Comparative effects of Escherichia coli strain M-17, metronidazole, and Escherichia coli strain M-17 plus metronidazole in dextran sulfate sodium-induced colitis

Before the administration of DSS (study day 7), there were no significant differences in the DAI scores among the treatment groups (Table 3). Also, during the pre-DSS phase of the study, only slight differences in water consumption were observed among all the treatment groups. Therefore, through this phase of the study, all mice tolerated the antibiotic and probiotic 
(a)
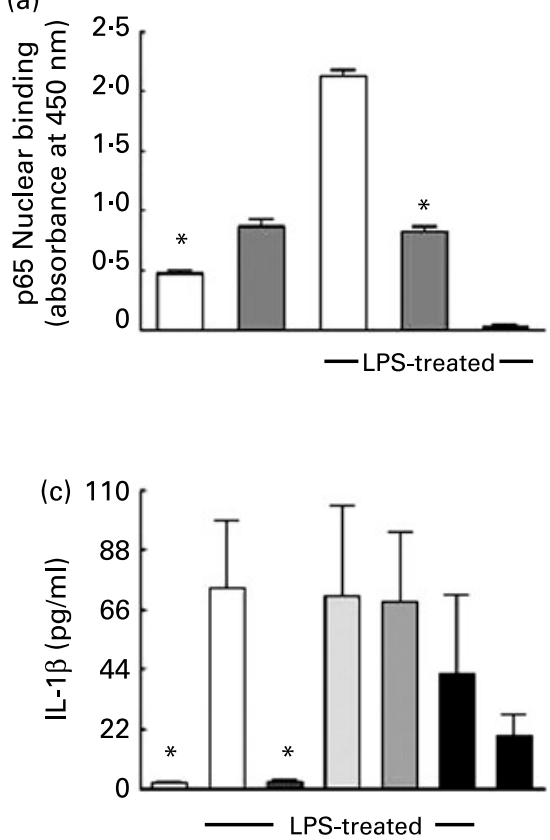

(b)
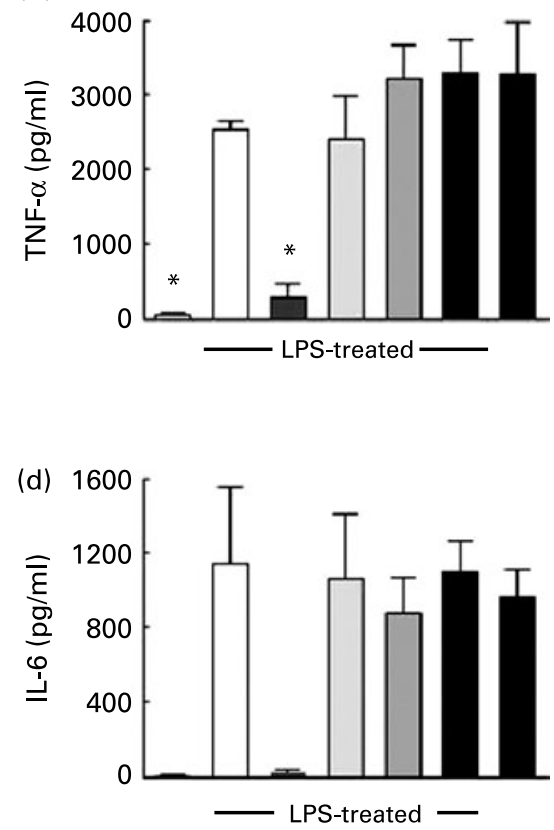

Fig. 2. (a) The effects of Escherichia coli strain M-17 (EC-M17) on NF-кB p65 in a RAW $264 \cdot 7$ cell line. The NF-кB signalling pathway was activated by treating the cells with lipopolysaccharide (LPS; $5 \mu \mathrm{g} / \mathrm{ml})$. Cells were treated with vehicle $(0.6 \%$ saline; $\square)$ or EC-M17 at $1 \times 10^{8}$ colony-forming units (cfu)/ml ( $\square$ ). EC-M17 was added immediately before LPS treatment and cells were collected for assay $3 \mathrm{~h}$ after LPS treatment. Exposure of the nuclear extract to a wild-type oligonucleotide, which competitively blocks 065 nuclear binding, constituted a positive control $(\boldsymbol{\square})$. * Mean value was significantly different from that of the vehicle-treated, LPS-treated control group $(P<0.05)$. Values are means from two experiments with their standard errors represented by vertical bars. (b-d) The effects of EC-M17, EC-M17-conditioned media (CM) and heat-killed EC-M17 on cytokine secretion in a RAW 264.7 cell line. The CM was prepared by adding EC-M17 to the macrophage culture medium for $5 \mathrm{~min}(\square)$ or for $2 \mathrm{~h}(\square)$. The cells were treated with vehicle $(0.6 \%$ saline; $\square)$, EC-M17 at $1 \times 10^{8} \mathrm{cfu} / \mathrm{ml}(\square)$, heat-killed EC-M17 (匹) prepared from a $1 \times 10^{8} \mathrm{cfu} / \mathrm{ml}$ concentration, or EC-M17 CM prepared from a $1 \times 10^{8} \mathrm{cfu} / \mathrm{ml}$ concentration. Except where indicated, macrophages were stimulated with the addition of LPS $(5 \mu \mathrm{g} / \mathrm{ml})$. Heat-killed EC-M17 and EC-M17 CM were added to the assay immediately before LPS treatment and culture media was collected for assay $4 \mathrm{~h}$ after LPS treatment. (b) TNF- $\alpha$ secretion in cells treated with and without LPS. * Mean value was significantly different from that of the vehicle-treated, LPS-treated control group $(P<0.05)$. (c) IL-1 $\beta$ secretion in cells treated with and without LPS. * Mean value was significantly different from that of the vehicle-treated, LPS-treated control group $(P<0.05)$. (d) IL-6 secretion in cells treated with and without LPS. The leftmost bar corresponds to vehicle-treated cells that were not exposed to LPS. Values are means from two or three experiments with their standard errors represented by vertical bars.

treatment regimens relatively well and no major overt effects were evident.

The administration of $2 \%$ DSS to otherwise untreated (vehicle/DSS) C57 BL/6 mice resulted in significant increases in DAI scores on days 12 and 13 when compared with vehicletreated mice that did not receive DSS (vehicle/water; Table 3). However, the increased DAI that was found in vehicle-treated mice was less prominent in mice treated with EC-M17, metronidazole, and EC-M17 plus metronidazole. On day 13, the DSS-treated group that also received EC-M17 (EC-M17/ DSS) had a mean DAI score $68.4 \%$ less, when compared with DSS-treated mice that also received vehicle $(P<0 \cdot 01)$. DSS-treated mice that received metronidazole (metronidazole/DSS) also had significantly reduced DAI $(P<0 \cdot 01)$, but the reduction was not as large $(47.4 \%)$. DSS-treated mice that received both EC-M17 and metronidazole (EC-M17 plus metronidazole/DSS) had significantly reduced DAI which was reflected in a more profound reduction in the mean DAI score $(78.9 \% ; P<0 \cdot 01)$. As on day 13 , treatment with EC-M17, metronidazole, and EC-M17 plus metronidazole significantly reduced $(P<0.01)$ the DAI as compared with vehicle/DSS treatment on day 12 (Table 3 ).

Water consumption values were generally similar in all of the treatment groups from days 7 to 12 . Water consumption ranged between 3.5 (SEM 3) and 4.5 (SEM 0.3) ml/d. However, on study day 13 , water consumption in the vehicle/DSS treatment group (2.0 (SEM 0.2$) \quad \mathrm{ml} / \mathrm{d})$ was significantly less $(P<0.05)$ than in all the other treatment groups.

Treatment of mice with EC-M17 (alone, or in combination with metronidazole) resulted in less shortening in colon length, as compared with that found in the vehicle/DSS-treated mice. On day 13 , the colon length values $(\mathrm{cm})$ were: $7 \cdot 1$ (SEM $0 \cdot 2$ ) for vehicle/water, $6 \cdot 4$ (SEM 0.1) for vehicle/DSS, 7.2 (SEM $0 \cdot 1$ ) for EC-M17/DSS, 6.8 (SEM 0.2) for metronidazole/DSS and 7.3 (SEM 0.1) for EC-M17 plus metronidazole/DSS. All of the colon length values in the probiotic and metronidazole treatment groups were significantly $(P<0.05)$ longer than the value found in the vehicle/DSS treatment group.

Effects of Escherichia coli strain M-17 on colonic cytokine levels in dextran sulfate sodium-induced colitis

The administration of $2 \%$ DSS to C57 BL/6 mice led to a 2.6-fold increase in the mean colonic IL-12 level (Fig. 3 (a)). On study day 13, mice treated with EC-M17, metronidazole, or a combination of these agents, had significantly lower levels of colonic IL-12 as compared with vehicle-treated mice. In mice treated with both EC-M17 and metronidazole, there was a $52 \%$ reduction in the colonic IL-12 content. In a similar fashion, following DSS administration, 
Table 3. Disease activity index (DAl) in C57 BL/6 mice over the $13 \mathrm{~d}$ course of the study* (Mean values with their standard errors)

\begin{tabular}{|c|c|c|c|c|c|c|c|c|c|c|}
\hline \multirow[b]{2}{*}{ Study day } & \multicolumn{2}{|c|}{$\begin{array}{c}\text { Vehicle/water } \\
(n 6) \dagger\end{array}$} & \multicolumn{2}{|c|}{$\begin{array}{l}\text { Vehicle/DSS } \\
\qquad(n 9) \dagger\end{array}$} & \multicolumn{2}{|c|}{$\begin{array}{l}\text { EC-M17/DSS } \\
(n 10) \dagger\end{array}$} & \multicolumn{2}{|c|}{$\begin{array}{l}\text { Metronidazo- } \\
\text { le/DSS }(n 10) \dagger\end{array}$} & \multicolumn{2}{|c|}{$\begin{array}{c}\text { EC-M17 } \\
\text { plus metronidazo- } \\
\text { le/DSS }(n 10) \dagger\end{array}$} \\
\hline & Mean & SEM & Mean & SEM & Mean & SEM & Mean & SEM & Mean & SEM \\
\hline 0 & 0 & 0 & 0 & 0 & 0 & 0 & 0 & 0 & 0 & 0 \\
\hline 2 & 0 & 0 & 0.1 & 0.1 & 0.4 & 0.2 & 0 & 0 & 0 & 0 \\
\hline 4 & 0 & 0 & 0.2 & 0.2 & 0.1 & 0.1 & 0.3 & 0.2 & 0.1 & 0.1 \\
\hline 6 & 0.2 & 0.2 & 0.3 & 0.2 & $0 \cdot 1$ & 0.1 & 0.2 & 0.1 & 0 & 0 \\
\hline 8 & 0.3 & 0.2 & 0.3 & 0.2 & 0 & 0 & 0.1 & 0.1 & 0 & 0 \\
\hline 10 & 0.2 & 0.2 & 0.6 & 0.2 & 0.7 & 0.3 & 0.7 & 0.2 & 0.8 & 0.2 \\
\hline 12 & 0.2 & 0.2 & $1.6 \ddagger$ & 0.2 & $0.3 \S$ & 0.2 & $0.6 \S$ & 0.2 & $0.3 \S$ & 0.2 \\
\hline 13 & 0 & 0 & $1.9 \ddagger$ & 0.1 & $0.6 \S$ & 0.2 & $1.0 \S$ & 0.2 & $0.4 \S$ & 0.2 \\
\hline
\end{tabular}

DSS, dextran sulfate sodium; EC-M17, Escherichia coli strain M-17.

* The DAI (0 to 40) was calculated as the sum of the scores for stool consistency and occult blood/gross bleeding divided by 2 (see Table 1).

†Excluding 'Study day,' column headers correspond to intervention/colitis induction. Colitis induction did not begin until day 7.

$\ddagger$ Mean value was significantly different from that of vehicle-treated, water-treated control group $(P<0.01)$.

$\S$ Mean value was significantly different from that of vehicle-treated, DSS-treated control group $(P<0.01)$.

there was a $3 \cdot 5$-fold increase in the colonic IFN- $\gamma$ content (Fig. 3 (b)). Animals treated with EC-M17, metronidazole, or both of these agents, had significantly lower levels of colonic IFN- $\gamma(P<0.05 \quad v$. vehicle/DSS $)$. In mice treated with both the probiotic and the antibiotic, the level of colonic IFN- $\gamma$ was virtually the same as in vehicle- and watertreated animals.
The ingestion of DSS resulted in a 52-fold increase in the mean colonic IL-1 $\beta$ level (Fig. 3 (c)). Lower mean IL-1 $\beta$ contents were observed in mice treated with EC-M17 (18.5\%; NS), metronidazole $(46.6 \% ; P<0.05)$, or a combination of these agents $(66.7 \% ; P<0.05)$ when compared with vehicletreated mice. Additionally, DSS-treated mice that received EC-M17 plus metronidazole had a significantly reduced
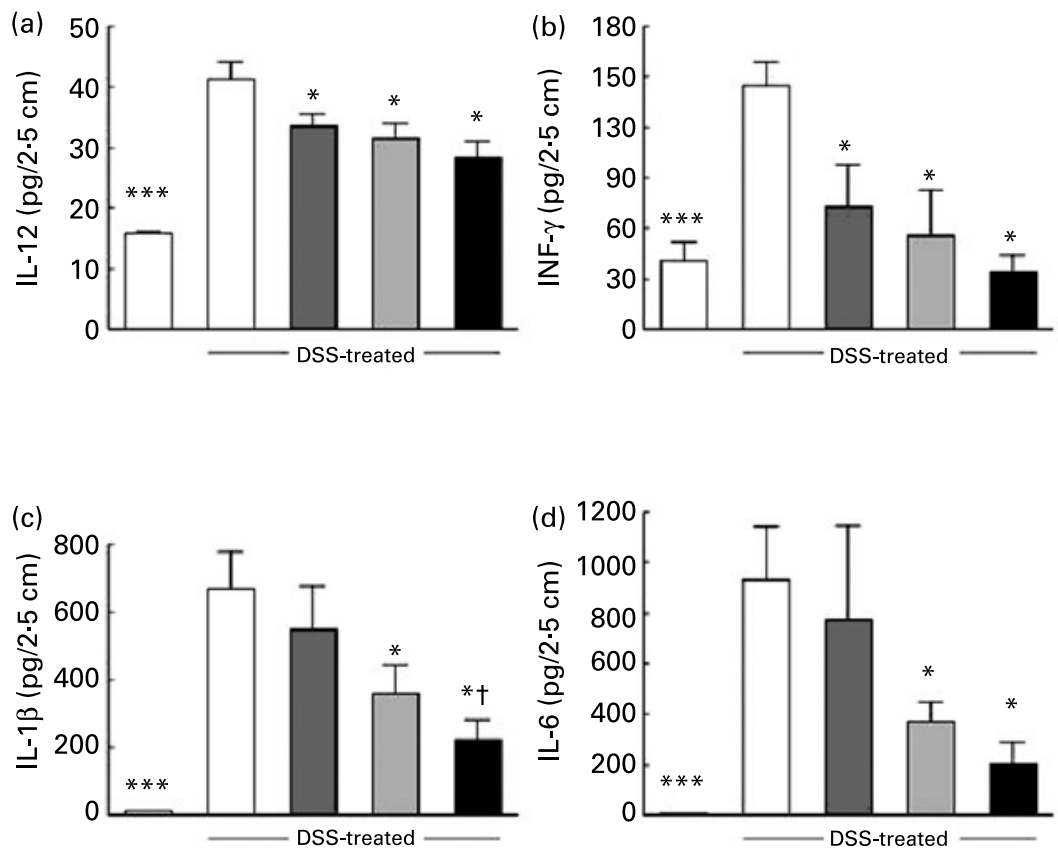

Fig. 3. The effects of oral administration of Escherichia coli strain M-17 (EC-M17) $\left(5 \mathrm{mg} / \mathrm{kg}\right.$ per d of a $5 \times 10^{9}$ concentration; $n 10$; $\square$ ), metronidazole (40 mg/kg per $\mathrm{d} ; n 10$; $)$ and EC-M17 plus metronidazole ( $5 \mathrm{ml} / \mathrm{kg}$ per d of a $5 \times 10^{9}$ concentration and $40 \mathrm{mg} / \mathrm{kg}$ per d, respectively; $n$ 10; ) on colonic levels of pro-inflammatory cytokines in C57 BL/6 mice. Also, there were six vehicle-treated animals $(\square)$ that did not undergo colitis induction with dextran sulfate sodium (DSS) and nine vehicle-treated $(\square)$ animals that underwent DSS colitis induction. (a) IL-12 content in DSS-treated and water-treated animals. Mean value was significantly different from that of the vehicle-treated, DSS-treated control group: ${ }^{*} P<0.05,{ }^{* * *} P<0.001$. (b) Interferon (IFN)- $\gamma$ level in DSS-treated and water-treated animals. Mean value was significantly different from that of the vehicle-treated, DSS-treated control group: ${ }^{*} P<0.05,{ }^{* * *} P<0.001$. (c) IL-1 $\beta$ content in DSS-treated and watertreated animals. Mean value was significantly different from that of the vehicle-treated, DSS-treated control group: ${ }^{\star} P<0.05$, ${ }^{\star \star \star}{ }^{*} P<0.001$. $\dagger$ Mean value was significantly different from that of the EC-M17-treated, DSS-treated control group $(P<0.05)$. (d) IL-6 level in DSS-treated and water-treated animals. The leftmost bar corresponds to the vehicle-treated group. Mean value was significantly different from that of vehicle-treated, DSS-treated control group: ${ }^{\star} P<0.05$, ${ }^{* \star \star} P<0.001$. Values are means with their standard errors represented by vertical bars. 
colonic IL-1 $\beta(P<0.05)$ when compared with DSS-treated mice that received EC-M17 only.

There was a very large increase (>200-fold) in colonic IL-6 with DSS treatment (Fig. 3 (d)). An overall reduction in IL-6 was noted in animals treated with EC-M17; however, a high IL-6 content in the colon of one of the probiotic-treated mice was responsible for the large standard error value and the failure to achieve statistical significance (compared with vehicle). Animals treated with metronidazole, or EC-M17 plus metronidazole, had significantly lower $(P<0.05)$ levels of colonic IL-6, as compared with vehicle-treated mice. In animals treated with both EC-M17 and metronidazole, there was a $78 \%$ reduction in the colonic IL- 6 content.

The colonic IL-10 content was attenuated in vehicle-treated mice that received DSS (114 (SEM 10) $\mathrm{pg} / 2.5 \mathrm{~cm}$ ) as compared with vehicle-treated mice that did not receive DSS (179 (SEM 20) $\mathrm{pg} / 2.5 \mathrm{~cm}$ ). However, there was no evidence that the probiotic and antibiotic treatment regimens increased the IL-10 level beyond that found in vehicle/DSS-treated mice. In a similar fashion to IL-10, the colonic IL-4 content was attenuated in vehicle/DSS-treated mice. Again, there was no evidence that the probiotic and antibiotic treatment regimens significantly increased the IL-4 level beyond that found in vehicle/DSS-treated mice (data not shown).

Effects of Escherichia coli strain M-17 on colonic myeloperoxidase and histology in dextran sulfate sodium-induced colitis

As shown in Fig. 4 (a), DSS-treated mice that received vehicle had a significant increase in the colonic MPO activity. These data indicate increased colonic neutrophil influx in these animals ${ }^{(26,29)}$. Mice treated with EC-M17, metronidazole, or a combination of these two agents had reduced levels of MPO (Fig. 4 (a)). The combined treatment regimen significantly reduced colonic MPO by $55.3 \%(P<0.05)$ compared with vehicle. Interestingly, the combined treatment regimen also significantly reduced colonic MPO by $38.2 \%(P<0.05)$ compared with EC-M17 treatment alone.

The vehicle/DSS-treated mice had evidence of more histological damage than their vehicle-treated counterparts that received water throughout the study. The mean colonic histology scores were significantly $(P<0 \cdot 05)$ reduced in EC-M17-treated mice, in metronidazole-treated mice, and in EC-M17 plus metronidazole-treated mice (Fig. 4 (b)). The combination of EC-M17 plus metronidazole reduced mean histology scores to a greater extent than metronidazole alone $(25.0 \% ; P<0.05)$.

A normal colonic architecture is evident in a representative photograph of a histology specimen obtained from an animal that did not receive DSS (Fig. 5 (a)). By comparison, the administration of DSS resulted in crypt damage (black arrows), significant numbers of leucocytes in the lamina propria (white arrow), as well as evidence of leucocytes in the submucosa (grey arrow; Fig. 5 (b)). In this vehicle/DSS-treated mouse there was also evidence of leucocytes (i.e. apparently macrophages) at the luminal surface. In the histology specimen of an EC-M17-treated mouse shown in Fig. 5 (c), there is evidence of some surface epithelial cell damage (black arrow), as well as mild inflammatory cell influx in the lamina propria (white arrow) and submucosa (grey arrow). In the animal treated with EC-M17 plus metronidazole (Fig. 5 (d)) the crypt architecture was preserved. There was only mild leucocyte infiltration in the lamina propria (white arrow). The pattern of colonic histology in this animal generally resembled that found in the vehicle/water-treated mouse.

\section{Effects of Escherichia coli strain M-17 on colonic nuclear factor- $\kappa B$ p65 in dextran sulfate sodium-induced colitis}

As found in the previous DSS-induced colitis study (see above), the mean DAI was significantly reduced $(P<0.05 v$. vehicle/ DSS) by EC-M17 treatment. Specifically, mean DAI scores on day 13 were: 0 (SEM 0 ) for vehicle/water, 0 (SEM 0) for EC-M17/water, 2.2 (SEM 0.2) for vehicle/DSS and 0.8 (SEM $0 \cdot 3$ ) for EC-M17/DSS. In conjunction with the acute DSS colitis model paradigm, expression of the NF- $\mathrm{KB}$ p65 subunit was examined. Representative Western blots from mouse colonic nuclear extracts are shown in Fig. 6. The actin data confirmed equal protein loading in the Western blot experiments. Overall, relatively little expression of p65 was found in the colons of animals that received water over a $13 \mathrm{~d}$ period (vehicle/water or EC-M17/water; Fig. 6 (a)). Specifically, relative densitometry values in these colonic samples were 0.04 (lane 1), 1.96 (lane 2), 0.78 (lane 3), 1.54 (lane 4) and 0.39 (lane 5). In contrast,
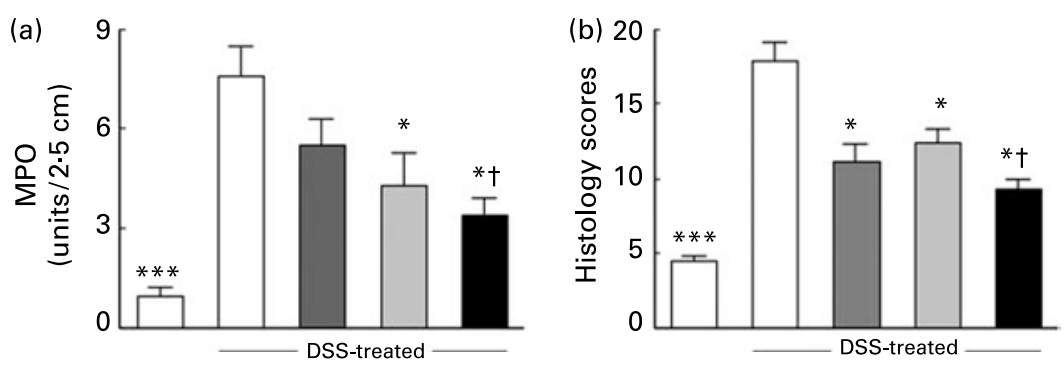

Fig. 4. The effects of oral administration of Escherichia coli strain M-17 (EC-M17) $\left(5 \mathrm{mg} / \mathrm{kg}\right.$ per d of a $5 \times 10^{9}$ concentration; $n 10$; $\left.\square\right)$, metronidazole (40 mg/kg per $\mathrm{d} ; n 10 ; \square)$ and EC-M17 plus metronidazole $\left(5 \mathrm{ml} / \mathrm{kg}\right.$ per d of a $5 \times 10^{9}$ concentration and $40 \mathrm{mg} / \mathrm{kg}$ per d, respectively; $\left.n 10 ; \mathbf{m}\right)$ on colonic levels of myeloperoxidase (MPO) and on histology scores in $\mathrm{C} 57 \mathrm{BL} / 6$ mice. Also, there were six vehicle-treated $(\square)$ animals that did not undergo colitis induction with dextran sulfate sodium (DSS) and nine vehicle-treated $(\square)$ animals that underwent DSS colitis induction. (a) MPO content in DSS-treated and water-treated animals. Mean value was significantly different from that of the vehicle-treated, DSS-treated control group: ${ }^{\star} P<0.05,{ }^{\star \star \star} P<0 \cdot 001$. $†$ Mean value was significantly different from that of the EC-M17-treated, DSS-treated control group $(P<0.05)$. (b) Histology scores in DSS-treated and water-treated animals. Mean value was significantly different from that of the vehicle-treated, DSS-treated control group: ${ }^{\star} P<0.05$, ${ }^{\star \star \star} P<0.001$. $†$ Mean value was significantly different from that of the metronidazole-treated, DSS-treated control group $(P<0.05)$. Values are means with their standard errors represented by vertical bars. 


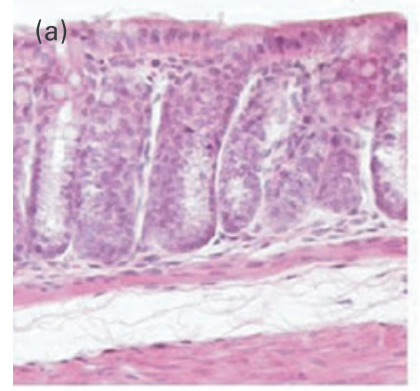

(b)

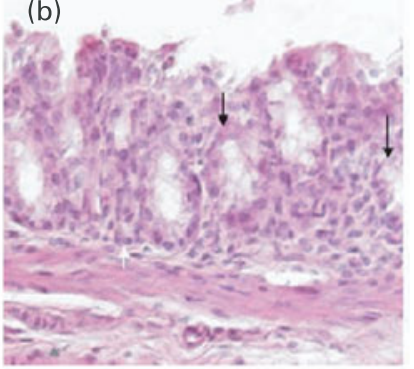

(c)

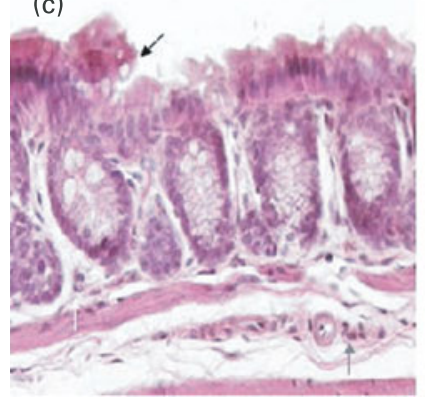

(a)

p65
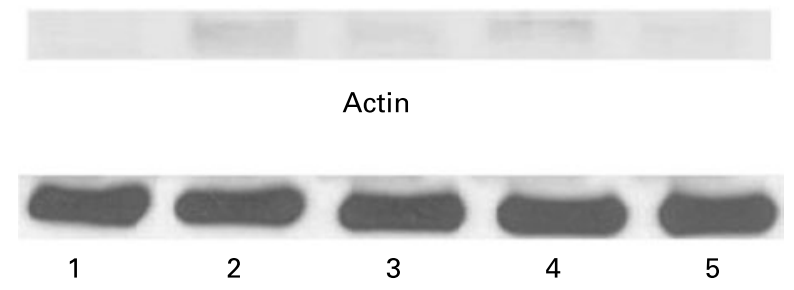

(b)

p65 (d)

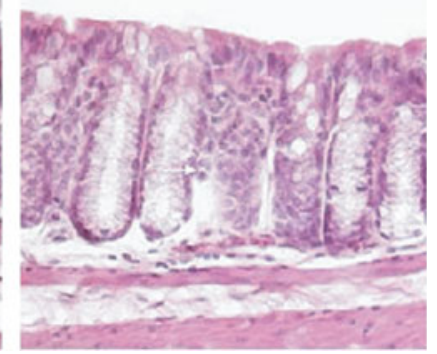

Fig. 5. Representative histology photographs of colonic specimens obtained on study day 13 following the oral administration of vehicle $(0.6 \%$ saline), Escherichia coli strain M-17 (EC-M17) $\left(5 \mathrm{ml} / \mathrm{kg}\right.$ per d of a $5 \times 10^{9}$ concentration), metronidazole $(40 \mathrm{mg} / \mathrm{kg}$ per d) and EC-M17 plus metronidazole $\left(5 \mathrm{ml} / \mathrm{kg}\right.$ per $\mathrm{d}$ of a $5 \times 10^{9}$ concentration and $40 \mathrm{mg} / \mathrm{kg}$ per $\mathrm{d}$, respectively) in C57 BL/6 mice that did (EC-M17, metronidazole, and EC-M17 plus metronidazole) or did not (vehicle) undergo dextran sulfate sodium (DSS) colitis induction. (a) Colonic histology of a vehicle-treated animal that did not receive DSS. (b) Colonic histology of a vehicle-treated animal that underwent DSS colitis induction. DSS caused crypt damage $(\rightarrow)$, significant numbers of leucocytes in the lamina propria $(\Leftrightarrow)$, as well as evidence of inflammatory cells in the submucosa $(\rightarrow)$. (c) Colonic histology of an EC-M17-treated animal that underwent DSS colitis induction. There was evidence of surface epithelial cell damage $(\rightarrow)$, as well as mild leucocyte influx in the lamina propria $(\Rightarrow)$ and submucosa $(\Rightarrow)$. (d) Colonic histology of an EC-M17 plus metronidazole-treated animal that received DSS. Notice that the crypt architecture was well preserved and only mild inflammatory cell influx is evident in the lamina propria $(\Rightarrow)$. This relatively normal colonic histology resembled that found in the vehicle-treated mouse that did not undergo DSS colitis induction. All images are at $200 \times$ magnification.

more prominent p65 expression was observed in animals that received $2 \%$ DSS in drinking water (vehicle/DSS group; Fig. 6 (b)). Relative densitometry values were 6.05 (lane 1), 1.02 (lane 2) and 4.75 (lane 3). However, the expression of p65 was less evident in DSS-treated mice that received the probiotic (EC-M17/DSS; Fig. 6 (b)). These densitometry values were 1.56 (lane 4), 0.05 (lane 5) and 1.09 (lane 6). Relative densitometry analyses compared all the p65 data to vehicle/water-treated mice (normalised value $=1 \cdot 0$ ). These analyses yielded the following fold changes in mean densitometry values: 0.91 for EC-M17/water, 2.52 for vehicle/DSS and 1.37 for EC-M17/DSS. These data suggest that p65 expression was enhanced in vehicle/DSS-treated animals and reduced in mice treated with EC-M17.

\section{Discussion}

IBD is a chronic inflammatory condition involving the intestine. IBD appears to involve the complex interactions between

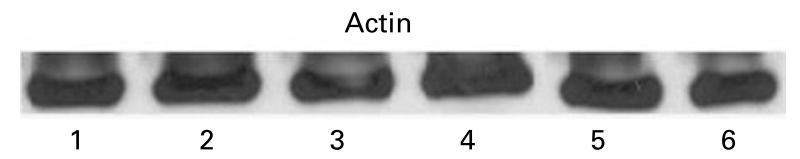

Fig. 6. The effects of vehicle ( $0.6 \%$ saline) in mice that did not consume dextran sulfate sodium (DSS) ( $n$ 2), Escherichia coli strain M-17 (EC-M17) $\left(5 \mathrm{ml} / \mathrm{kg}\right.$ per $\mathrm{d}$ of a $5 \times 10^{9}$ concentration) in mice that did not consume DSS $(n 3)$, vehicle in mice that underwent DSS colitis induction $(n 5)$ and EC-M17 $\left(5 \mathrm{ml} / \mathrm{kg}\right.$ per $\mathrm{d}$ of a $5 \times 10^{9}$ concentration) in mice that underwent DSS colitis induction $(n 4)$ on colonic p65 expression. Nuclear extracts were obtained from colonic homogenates. The Western blot analysis of NF-кB p65 was performed using $30 \mu \mathrm{g}$ protein per sample. The actin bands confirmed equal protein loading in these experiments. (a) Representative colonic p65 expression results in mice that did not receive DSS colitis. Lanes 1 and 2, vehicle; lanes 3 to 5, EC-M17. Relative densitometry values for these colonic extracts, as calculated in the Methods section, were: 0.04 (lane 1), 1.96 (lane 2), 0.78 (lane 3), 1.54 (lane 4) and 0.39 (lane 5). (b) Representative colonic p65 expression in mice that were given $2 \%$ DSS in the drinking water. Lanes 1 to 3 , vehicle; lanes 4 to 6 , EC-M17. Relative densitometry values for these colonic samples were: 6.05 (lane 1), 1.02 (lane 2), 4.75 (lane 3), 1.56 (lane 4), 0.05 (lane 5) and 1.09 (lane 6).

the immune system, endogenous intestinal epithelial cells and the local luminal environment that contains high concentrations of commensal bacteria. These interactions lead to an unrestrained, exaggerated immune response resulting in intestinal inflammation ${ }^{(30)}$.

This immune response is characterised by activation of the NF- $\kappa \mathrm{B}$ signalling system as well as secretion of relevant proinflammatory cytokines, such as TNF- $\alpha$, IL-1 $\beta$ and IL- $6^{(8,11)}$. In this regard, $\mathrm{NF}-\kappa \mathrm{B}$ is clearly up-regulated in the intestines of IBD patients ${ }^{(31-33)}$. For example, the p65 component of the $\mathrm{NF}-\kappa \mathrm{B}$ heterodimer was reported to be highly activated in epithelial cells and in lamina propria macrophages obtained from patients with active Crohn's disease and ulcerative colitis ${ }^{(31)}$. Long-standing therapies, such as corticosteroids and 5-aminosalicylic acid, may work, in part, by inhibiting NF- $\mathrm{K}^{(33-35)}$. More

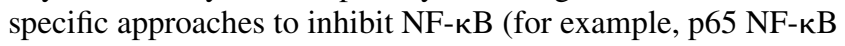
antisense therapy) have also demonstrated efficacy in animal models of $\operatorname{IBD}^{(18,19,26,29)}$. Recently, it was demonstrated that various bacteria strains (including probiotics) are also capable of inhibiting NF- $\kappa \mathrm{B}$ and pro-inflammatory cytokines in various types of cells, including macrophages ${ }^{(4,12,36,37)}$.

Our in vitro results showed that the novel probiotic agent, EC-M17, at a relatively low concentration $\left(1 \times 10^{8} \mathrm{cfu} / \mathrm{ml}\right)$, could significantly attenuate the activation of NF- $\mathrm{KB}$ in two 
cell lines. Moreover, EC-M17 attenuated NF- $\kappa$ B in response to different inducing agents (TNF- $\alpha$ or LPS), thereby suggesting that this inhibition occurred at the post-receptor level. In concordance with the inhibition of LPS-induced p65 nuclear binding in a murine macrophage cell line, the secretion of NF- $\kappa \mathrm{B}$-dependent cytokines (TNF- $\alpha$, IL-1 $\beta$ and IL-6) was dramatically inhibited by treatment with live EC-M17.

Interestingly, probiotic bacteria have shown varying effects on NF- $\mathrm{KB}$ in studies conducted in different cell lines. For example, Bifidobacterium infantis and Lactobacillus salivarius inhibited NF- $\kappa$ B to some degree in the HT-29 epithelial cell line ${ }^{(38)}$. In a clinically relevant study, using a tissue culture system with intestinal mucosal biopsies from IBD patients, B. longum clearly inhibited NF- $\kappa \mathrm{B}$ activation in lamina propria mononuclear cells ${ }^{(39)}$. By comparison, a commonly used probiotic (E. coli Nissle 1917) was found to activate the $\mathrm{NF}-\kappa \mathrm{B}$ pathway in intestinal epithelial cells, as well as in isolated murine lymphocytes ${ }^{(40,41)}$. Similarly, B. lactis activated $N F-\kappa B$ in intestinal epithelial cell lines ${ }^{(42)}$. Therefore, bacterial strain and species differences apparently exist with respect to the effects of probiotics on NF- $\kappa \mathrm{B}$. Based on our in vitro results (Figs. 1 and 2), EC-M17 and E. coli Nissle 1917 may have distinct effects on the NF- $\kappa$ B signal transduction system ${ }^{(40,41)}$. It would be interesting in future studies to directly compare the effects of these two E. coli probiotics on the NF- $\kappa \mathrm{B}$ pathway by conducting parallel studies in the same cell lines.

In our studies, only live EC-M17 were effective in inhibiting NF- $\kappa \mathrm{B}$ signalling in murine macrophages; therefore, it is possible that EC-M17 delivers effector proteins directly into host cells, as has been suggested for other strains of E. coli $^{(36,43)}$. This possibility is reinforced by our data from the RAW 264.7 cell line, which showed that heat-killed EC-M17, as well as EC-M17 conditioned media, was not effective in reducing cytokine secretion by macrophages. These results suggest that the robust inhibitory effects of EC-M17 on these NF-кBdependent cytokines required live bacteria, and not a secreted metabolite or a degradation product. Our findings are not in agreement with those of some other investigators. For example, Menard et al. ${ }^{(44)}$ found that secreted metabolites from two probiotics (B. breve and Streptococcus thermophilus) inhibited $\mathrm{NF}-\kappa \mathrm{B}$ signalling and TNF- $\alpha$ secretion by monocytes.

Metronidazole has been used to treat IBD patients for dec$\operatorname{ades}^{(45,46)}$. This antibiotic was selected as one of the pharmacological interventions in the present study because of its historical use as an IBD therapy, as well as to test for possible additive effects when given together with EC-M17. While metronidazole may have some intrinsic anti-inflammatory properties, its efficacy, as well as the efficacy of other antibiotics similarly employed, is probably related to a reduced burden of pro-inflammatory mucosal bacteria ${ }^{(47,48)}$. In this regard, we found no evidence that metronidazole inhibited LPS-induced cytokine secretion by murine macrophages.

The aetiology of DSS-induced colitis is thought to be multifactorial in nature, involving both direct toxic effects on the mucosa, as well as the influx of inflammatory cells ${ }^{(15-17)}$. As with IBD, bacteria probably play a role in the pathogenesis of DSS-induced colitis, because it has been reported that antibiotics improve this colitis ${ }^{(16,24,49)}$. Moreover, various probiotics also improve DSS-induced colitis in rodents ${ }^{(13,14)}$.
An increased DAI, a reduction in colon length, enhanced colonic levels of pro-inflammatory cytokines, increased colonic MPO activity, and more severe colonic histological damage are consistent findings in DSS-treated animals. These parameters are often used as markers of colonic injury $^{(12,26,50,51)}$. Our findings indicate that both symptomatic (DAI) and gross morphological (colon length) parameters of colitis were significantly improved in the antibiotic and probiotic treatment groups, individually and also when administered in combination. In this regard, there was only a $40 \%$ incidence of colonic symptoms (loose and bloody stools) in mice treated with the probiotic plus antibiotic, while this incidence was $100 \%$ in vehicle-treated controls. Our data are also consistent with the findings of other investigators who found that probiotics can inhibit the production of pro-inflammatory cytokines $^{(12,51)}$. Interestingly, our data suggest that more prominent reductions of some pro-inflammatory cytokines were obtained with combined EC-M17 and metronidazole treatment (Fig. 3 (b) and (c)). Consistent with this cytokine data, the overall magnitude of the inhibitory effects on MPO and colonic histology were also more profound in probiotic plus antibiotic-treated animals (Fig. 4).

Since production of these pro-inflammatory cytokines (TNF- $\alpha$, IL-1 $\beta$ and IL-6) is dependent on activation of NF$\kappa \mathrm{B}$, the effects of EC-M17 on the NF- $\kappa \mathrm{B}$ signalling system were also examined in the DSS-induced colitis model ${ }^{(8-11)}$. Interestingly, the administration of EC-M17 to DSS-treated mice resulted in attenuated nuclear expression of the NF- $\kappa \mathrm{B}$ p65 subunit (Fig. 6 (b)). The nuclear expression of the p65 subunit has previously been shown to be up-regulated during DSS-induced colitis, and is thought to play a critical role in promoting intestinal inflammation ${ }^{(18,19)}$. Taken as a whole, these results suggest that reductions in the parameters of DSS-induced colitis, including pro-inflammatory cytokine levels, may have resulted from the inhibition of NF- $\mathrm{kB}$ signalling by EC-M17. This statement is supported by our in vitro data showing that EC-M17 inhibited the nuclear binding of NF- $\kappa \mathrm{B}$ in murine macrophages (Fig. 2).

In the present study, the colonic level of IL-10 was decreased in vehicle-treated mice given DSS. It is possible that this attenuation of IL-10 contributed to the development of colitis, since IL-10 is a well-known immunomodulatory cytokine $^{(16,52)}$. Previously, other investigators reported that the administration of probiotics to mice could induce the production of IL-10 and transforming growth factor- $\beta$-bearing regulatory cells, and that these cells contributed to the attenuation of murine colitis ${ }^{(52)}$. EC-M17 treatment (alone or in combination) did not induce colonic levels of the regulatory cytokine, IL-10. These differences in IL-10 induction most probably relate to species differences between EC-M17 and VSL\#3 (a probiotic food supplement), which contains a combination of Bifidobacterium, Lactobacillus and Streptococcus bacteria $^{(4,12)}$.

Our data support the contention that the major anti-colitis action of EC-M17 is by modulation of immune processes ${ }^{(1)}$. Further, the additive effects of EC-M17 and metronidazole in DSS-induced colitis suggest that the predominant mechanisms for the antibiotic and probiotic are distinct. Immunomodulation, as a mechanism of action for EC-M17, is consistent with the results reported herein on the modulation of NF-кB p65 and pro-inflammatory cytokine levels in mice 
administered EC-M17. Our theory is reinforced by the fact that metronidazole did not directly inhibit the secretion of pro-inflammatory cytokines by RAW 264.7 macrophages, while EC-M17 clearly showed an anti-cytokine profile. Changes in the intestinal environment due to antibiotic treatment may have eliminated pro-inflammatory bacteria in the murine colonic milieu. In this regard, metronidazole is known to reduce anaerobic bacteria (for example, Bacteroides species) that appear to contribute to the aetiology of DSSinduced colitis ${ }^{(24)}$. A similar metronidazole-mediated mechanism may have been operative in the present study. However, it also remains possible that other mechanisms may have contributed to the anti-colitis activity observed in the present study. For example, metronidazole treatment could also have better enabled EC-M17 to become a more dominant bacterial species in the intestinal environment. Thereby, EC-M17 would persist in greater amounts within the host organism relative to other commensal bacteria, by a competitive exclusion type of mechanism $^{(1)}$. This possibility remains to be determined in future studies with EC-M17.

In summary, in vitro treatment of two cell lines with live EC-M17 resulted in inhibition of the NF- $\mathrm{KB}$ signalling pathway and p65 nuclear binding. Moreover, the probiotic attenuated the secretion of pro-inflammatory cytokines by macrophages. In vivo, EC-M17 effectively improved various histological, biochemical, morphological and symptomatic parameters of DSS-induced colitis in mice. Combined treatment with EC-M17 plus metronidazole proved to be generally more effective in DSS-induced colitis in mice than either alone. The data from this study suggest that EC-M17 could prove to be clinically useful for the treatment of intestinal inflammatory diseases. Moreover, further research with the probiotic is warranted. Finally, the combination of EC-M17 plus an antibiotic may afford therapeutic advantages that should also be investigated in future studies.

\section{Acknowledgements}

The authors acknowledge the following potential conflicts of interests. The study was supported by a grant from The BioBalance Corporation to L. R. F. Also, R. A. H. and E. F. B. are employees of The BioBalance Corporation.

All authors contributed to the intellectual aspects (L. R. F., R. A. H., E. F. B., W. A. K.) and/or technical aspects (L. R. F., J. S., L. M.) of this manuscript.

\section{References}

1. Fedorak RN \& Madsen KL (2004) Probiotics and the management of inflammatory bowel disease. Inflamm Bowel Dis 10, 286-299.

2. Shanahan F (2005) Physiological basis for novel drug therapies to treat the inflammatory bowel diseases: I. Pathophysiological basis and prospects for probiotic therapy in inflammatory bowel disease. Am J Physiol Gastrointest Liver Physiol 288, G417-G421.

3. Strober W (1998) Interactions between epithelial cells and immune cells in the intestines. Ann N Y Acad Sci 859, 37-45.

4. Petrof EO, Kojima K, Ropeleski MJ, Musch MW, Tao Y, De Simone C \& Chang EB (2004) Probiotics inhibit nuclear factor- $\mathrm{\kappa B}$ and induce heat shock proteins in colonic epithelial cells through proteasome inhibition. Gastroenterology 127, 1474-1487.

5. Baeuerle PA \& Henkel T (1994) Function and activation of NF$\kappa \mathrm{B}$ in the immune system. Annu Rev Immunol 12, 141-179.

6. Baldwin AS (1996) The NF-кB and IкB proteins: new discoveries and insights. Annu Rev Immunol 14, 649-683.

7. Tak PP \& Firestein GS (2001) NF-кB: a key role in inflammatory disease. J Clin Invest 107, 7-11.

8. Jobin C \& Sartor RB (2000) NF- $\mathrm{B}$ signaling proteins as therapeutic targets for inflammatory bowel diseases. Inflamm Bowel Dis 6, 206-213.

9. Jobin C \& Sartor RB (2000) The IкB/NF-кB system. A key determinant of mucosal inflammation and protection. Am J Physiol Cell Physiol 278, C451-C462.

10. Lee JI \& Burckart GJ (1998) Nuclear factor-кB: important transcription factor and therapeutic target. J Clin Pharmacol 38, 981-993.

11. Schottelius AJG \& Baldwin AS (1999) A role for transcription factor NF-кB in intestinal inflammation. Int $J$ Colorectal Dis 14, $18-28$.

12. Jijon H, Backer J, Diaz H, Yeung H, Thiel D, McKaigney C, De Simone C \& Madsen K (2004) DNA from probiotic bacteria modulates murine and human epithelial and immune function. Gastroenterology 126, 1358-1373.

13. Osman N, Adawi D, Ahrne S, Jeppsson B \& Molin G (2004) Modulation of the effect of dextran sulfate sodium-induced acute colitis by the administration of different probiotic strains of Lactobacillus and Bifidobacterium. Dig Dis Sci 49, 320-327.

14. Arakai Y, Andoh A, Takizawa J, Takizawa W \& Fujiyama Y (2004) Clostridium butyricum, a probiotic derivative, suppresses dextran sulfate sodium-induced experimental colitis in rats. Int $J$ Mol Med 13, 577-580.

15. Egger B, Bajaj-Elliott M, MacDonald TT, Inglin R, Eyesselein VE \& Buchler MW (2000) Characterization of acute murine dextran sodium sulphate colitis: cytokine profile and dose dependency. Digestion 62, 240-248.

16. Strober W, Fuss IJ \& Blumberg RS (2002) The immunology of mucosal models of inflammation. Annu Rev Immunol 20, 495-549.

17. Kitajima S, Takuma S \& Morimoto M (1999) Changes in colonic mucosal permeability in mouse colitis induced with dextran sulfate sodium. Exp Anim 48, 137-143.

18. Spiik AK, Ridderstad A, Axelsson LG, Midtvedt T, Bkork L \& Pattersen S (2002) Abrogated lymphocyte infiltration and lowered CD14 in dextran sulfate induced colitis in mice treated with p65 oligonucleotides. Int J Colorectal Dis 17, 223-232.

19. Murano M, Maemura K, Hirata I, Toshina K, Nishiwaka T, Hammamoto N, Sasaki S, Saitoh O \& Katsu K (2000) Therapeutic effect of intracolonically administered nuclear factor кB (p65) antisense oligonucleotide on mouse dextran sulphate sodium (DSS)-induced colitis. Clin Exp Immunol 120, 51-58.

20. Adler SN, Jacob H \& Eliakim R (2003) The probiotic agent $E$ coli strain ATCC20226 has a healing effect on proximal inflammation in the small bowel (Abstract). Gastroenterology 120, A-527.

21. Bogomolov BP \& Genina GS (1979) Клиническая оценказффективности колибактерина при лечении больных дизентерией иего рооли в восстановлении биоцќ еноза (Clinical evaluation of colibacterin in the treatment of patients with dysentery and its role in restoration of biocenosis). Ter Arkh 51, 94-98.

22. Kurnosova NA, Zatsepin IuK \& Feklisova LV (1979) Биологические препараты в комплексной терапии детей - реконвалесцентов после дизентерии (Biological preparations in the overall therapy of children convalescing after dysentery). Zh Mikrobiol Epidemiol Immunobiol, April, 21-25. 
23. Kokesova A, Frolova L, Kvberka M, Sokol D, Rossmann P, Bartova J \& Tlaskalova-Hogenova H (2006) Oral administration of probiotic bacteria (E. coli Nissle, E. coli O83, Lactobacillus casei) influences the severity of dextran sodium sulfate-induced colitis in BALB/c mice. Folia Microbiol (Praha) 51, 478-484.

24. Rath HC, Schulz M, Freitag R, Dieleman LA, Li F, Linde HJ, Scholmerich J \& Sartor RB (2001) Different subsets of enteric bacteria induce and perpetuate experimental colitis in rats and mice. Infect Immun 69, 2277-2285.

25. Murthy SNS, Cooper HS, Shim H, Shah RS, Ibrahim SA \& Sedergan DJ (1993) Treatment of dextran sulfate sodiuminduced murine colitis by intracolonic cyclosporine. Dig Dis Sci 38, 1722-1734.

26. Fitzpatrick LR, Wang J \& Le T (2000) In vitro and in vivo effects of gliotoxin, a fungal metabolite: efficacy against dextran sodium sulfate-induced colitis in rats. Dig Dis Sci $\mathbf{4 5}$, 2327-2336.

27. Krieglstein CF, Cerwinka WH, Laroux FS, Grisham MB, Schurmann G, Bruwer M \& Granger DN (2001) Role of appendix and spleen in experimental colitis. J Surg Res 101, 166-175.

28. Williams KL, Fuller CR, Dieleman LA, DaCosta CM, Haldeman KM, Sartor RB \& Lund PK (2001) Enhanced survival and mucosal repair after dextran sodium sulfate-induced colitis in transgenic mice that overexpress growth hormone. Gastroenterology 120, 925-937.

29. Fitzpatrick LR, Wang J \& Le T (2002) Gliotoxin, an inhibitor of nuclear factor- $\mathrm{\kappa B}$, attenuates peptidoglycan-polysaccharideinduced colitis in rats. Inflamm Bowel Dis 8, 159-167.

30. Bouma G \& Strober W (2003) The immunological and genetic basis of inflammatory bowel disease. Nat Rev Immunol 3 521-533.

31. Neurath MF, Becker C \& Barbulescu K (1998) Role of NF-кB in immune and inflammatory responses in the gut. Gut 43, 856-860.

32. Rogler G, Brand K, Vogl D, Page S, Hofmeister R, Andus T, Knueshel R, Bauerle PA, Schlomerich J \& Gross V (1998) Nuclear factor $\kappa \mathrm{B}$ is activated in macrophages and epithelial cells of inflamed intestinal mucosa. Gastroenterology 115, 357-369.

33. Thiele K, Bierhaus A, Autschbach F, Hofmann M, Stremmel W, Thiele H \& Ziegler R (1999) Cell specific effects of glucocorticoid treatment on the NF-кB p65/ІкB $\alpha$ system in patients with Crohn's disease. Gut 445, 693-704.

34. Nikolaus S, Folsch UR \& Schreiber S (2000) Immunopharmacology of 5-aminosalicylic acid and of glucocorticoids in the therapy of inflammatory bowel disease. Hepatogastroenterology 47, 71-82.

35. Yan FY \& Polk DB (1999) Aminosalicylic acid inhibits IkB kinase $\alpha$ phosphorylation of IкB $\alpha$ in mouse intestinal epithelial cells. J Biol Chem 274, 36631-36636.

36. Hauf $N$ \& Chakraborty $T$ (2003) Suppression of NF-кB activation and proinflammatory cytokine secretion by Shiga toxin-producing Escherichia coli. J Immunol 170, 2074-2082.

37. Selvaraj SK \& Prasadarao NV (2005) Escherichia coli K1 inhibits proinflammatory cytokine induction in monocytes by preventing NF-кB activation. $J$ Leukoc Biol 78, 544-554.

38. O'Hara AM, O'Regan P, Fanning A, O'Mahony C, Macsharry J, Lyons A, Bienenstock J, O'Mahony L \& Shanahan F (2006) Functional modulation of human intestinal epithelial cell responses by Bifidobacterium infantis and Lactobacillus salivarius. Immunology 118, 202-215.

39. Bai AP, Ouyang Q, Xiao XR \& Li SF (2006) Probiotics modulate inflammatory cytokine secretion from inflamed mucosa in active ulcerative colitis. Int J Clin Pract 60, 284-288.

40. Grabig A, Paclik D, Gurzy C, et al. (2006) Escherichia coli strain Nissle 1917 ameliorates experimental colitis via toll-like receptor 2- and toll-like receptor 4-dependent pathways. Infect Immun 74, 4075-4082.

41. Wehkamp J, Harder J, Wehkamp K, et al. (2004) NF-кB- and AP-1-mediated induction of human defensin-2 in intestinal epithelial cells by Escherichia coli Nissle 1917; a novel effect of a probiotic bacterium. Infect Immun 72, 5750-5758.

42. Ruiz PA, Hoffman M, Szcesnys S, Blaut M \& Haller D (2005) Innate mechanisms for Bifidobacterium lactis to activate transient pro-inflammatory host responses in intestinal epithelial cells after the colonization of germ-free rats. Immunology 115, 441-450.

43. Maresca M, Miller D, Quitaed S, Dean P \& Kenny B (2005) Enteropathogenic Escherichia coli (EPEC) effector-mediated suppression of antimicrobial nitric oxide production in a small intestinal epithelial model system. Cell Microbiol 7, $1749-1762$.

44. Menard S, Candalh C, Bambou JC, Terpend K, Cerf-Bensussan N \& Heyman M (2004) Lactic acid bacteria secrete metabolites retaining anti-inflammatory properties after intestinal transport. Gut 53, 821-828.

45. Blichfeldt P, Blomhoff JP, Myhre E \& Gjone E (1978) Metronidazole in Crohn's disease. Scand J Gastroenterology 13, $123-127$

46. Ursing B \& Kamme G (1975) Metronidazole for Crohn's disease. Lancet i, 775-777.

47. Lahat G, Halperin D, Barazovsky E, Shalit I, Rabau M, Klausner J \& Fabian I (2007) Immodulatory effects of ciprofloxacin in TNBS-induced colitis in mice. Inflamm Bowel Dis 13, $557-565$

48. Rutgeerts P, Hiele M, Geboes K, Peeters M, Penninckx F, Aerts $\mathrm{R}$ \& Kerremans R (1995) Controlled trial of metronidazole treatment for the prevention of Crohn's recurrence after ileal resection. Gastroenterology 108, 1617-1621.

49. Hans W, Scholmerich J, Gross V \& Falk W (2000) The role of resident intestinal flora in acute and chronic dextran sulfate sodium-induced colitis in mice. Eur J Gastroenterol Hepatol 12, 267-273.

50. Gaudio E, Taddei G, Vetuschi A, Sferrea R, Frieri G, Ricciardi G \& Caprilli R (1999) Dextran sulfate sodium (DSS) colitis in rats. Clinical, structural and ultrastructural aspects. Dig Dis Sci 44, 1458-1475.

51. Schultz M, Strauch UG, Linde HJ, Watzl S, Obermeir F, Gottl C, Dunger N, Grunwald N, Scholmerich J \& Rath HC (2004) Preventive effects of Escherichia coli strain Nissle 1917 on acute and chronic intestinal inflammation in two different murine models of colitis. Clin Diagn Lab Immunol 11, 372-378.

52. Di Giacinto C, Marinaro M, Sanchez M, Strober W \& Boirvant M (2005) Probiotics ameliorate recurrent Th-1 mediated murine colitis by inducing IL-10 and IL-10 dependent TGF- $\beta$ bearing regulatory cells. J Immunol 174, 3237-3246. 